\begin{abstract}
Internationalization is a key aim of the International Society of Political Psychology (ISPP). This paper uses bibliometric techniques to explore international collaborations in the Society's core activities, namely the journal Political Psychology and annual meetings. We explore how authors from different regions of the world are interconnected through coauthorship, using country information extracted from authors' affiliation and coded as WEIRD (Western, Educated, Industrialised, Rich and Democratic) or non-WEIRD. Study 1 analyzed co-authorship in the Society's journal Political Psychology from 1985-2014 (30 years), with 1,151 authors from 42 countries and 1,337 co-authorship ties between them. Study 2 mapped the co-authorship relationships for annual meetings for which documentation was available, eventually collecting data from 2006-2014 (eight years). In total, 4,260 authors from 74 countries were represented, with 6,884 collaborative ties. Annual meetings reflected more international collaboration than the journal on several dimensions, including a large internationally connected giant component of collaborating authors evident in annual meetings, but not the journals. In annual meetings, there were more collaborations between WEIRD and non-WEIRD authors. However, even at annual meetings, deep internationalization involving non-WEIRD authors was rare, and the activities of the Society primarily represent academics from WEIRD countries, particularly the USA.
\end{abstract}

Keywords: internationalization, political psychology, co-authorship analysis, bibliometric, ISPP

Exploring internationalization within the International Society for Political Psychology: A bibliometric co-authorship network analysis of two core ISPP dissemination activities 
This paper contributes to the small body of work taking stock of the discipline of political psychology (Nesbitt-Larking \& Kinnvall, 2011). Here, we explore its social and geographic structure through co-authorship analysis of the dissemination activities of the International Society of Political Psychology - specifically, of publications in its flagship journal Political Psychology and presentations at annual meetings. This project does not contribute directly to disciplinary knowledge, but applies the scientific method to the field itself. This science of science (increasingly called metascience) can provide insights into practices and social structures of the field that ultimately improve scientific practices, results and theory (Enserink, 2018). In this paper, we focus on the extent and type of internationalization in the Society's activities by analysing the trace evidence of collaboration in co-authorship relationships (Glänzel \& Schubert, 2004).

Political psychology is an interdisciplinary academic field at the intersection of political science and psychology (Perry, 2011), broadly focused on understanding politics and political processes, structures, perceptions, experiences and behavior from a psychological perspective (Cottom, Dietz-Uhler, Mastors, \& Preston, 2010; Huddy, Sears, \& Levy, 2013). It has experienced rapid growth, and has become an influential area of research in social science. Theoretical and practical approaches of political psychology have been applied in many BBC News contexts, including leadership roles, domestic and foreign policy-making, behavior in ethnic violence, war, genocide, group dynamics and conflict, racist attitudes and behavior, voting, nationalism, and political extremism (Cottom et al., 2010; Huddy et al., 2013). Historically, political psychology has drawn heavily on social psychological approaches designed to explore the nature and underlying foundations of human social and political behavior, but potentially (and increasingly) it applies a broader range of theoretical and methodological paradigms (Hatemi \& McDermott, 2012; Huddy et al.,2013).

Geographically, political psychology is most obviously well established in North America and Europe, and most prominent publications are in English; however, it also seems to be developing and thriving in other parts of the world (Suedfeld \& Hansen, 2006). In Latin 
America particularly, the discipline has a long history and has grown consistently (Polo, Godoy, Imhoff, \& Brussino, 2014). Several South American national and international organisations and journals are specifically dedicated to political psychology (e.g. Hur \& Sabucedo, 2017). In other regions, political psychology is sufficiently well established for local reviews to be written on the state of the field, including in China (Shen, 2007), Ukraine

(Bondarevskaya \& Tkalych, 2010), and Russia (Chmyreva, 2015). Although searching for “political psychology” emanating from Africa yields few results (especially outside of South Africa), this is partly because many researchers doing this work are not labeling it as such (see, for example, many publications in African Affairs, e.g. Wahutu, 2017). Generally, work from the periphery tends to be relatively unknown elsewhere, for reasons discussed in more detail below (Nesbitt-Larking, 2014).

The International Society of Political Psychology (ISPP) describes itself as an “interdisciplinary organization representing all fields of inquiry concerned with exploring the relationships between political and psychological processes" (ISPP, 2019a). Although nominally focused on "political psychology," in practice the focus of members and contributors is much broader, extending across disciplines such as political science, communications, economics, sociology, gender studies, governance, and public administration (Huddy et al., 2013). Indeed, the broad range of disciplines represented in

ISPP activities reflects the society's success in operationalizing its vision "to facilitate communication of scientific research, theory, and practice across disciplinary, national, and ideological boundaries, both among members of the Society and those outside the Society" (ISPP, 2015, p. 1). Importantly, the contributors to the journal Political Psychology and the ISPP annual meetings include many non-members who represent the field more generally.

While the composition of the Society and its goals make it a good case to explore the evolving patterns of internationalization in the field of political psychology in general, there is also a case to be made for studying internationalization in the Society more specifically. The ISPP was founded in 1978 in Los Angeles, USA, and the central office is located in North 
Carolina, USA (ISPP, 2019a). Yet, despite its American origins, it was explicitly established as an international society, and internationalization is a core constitutional goal.

However, of the first 21 annual meetings, 14 were in North America (ISPP, 2019b). In 1998, "the ratio of US to non-US conference participants in the preliminary program [was] 1.8-to-1 ... [compared to] the 2.2-to-1 ratio in the total membership" (ISPP, 1998a, p. 1). By then, the Society was already making concerted efforts towards more global recruitment. For example, the 1998 membership committee included representatives responsible for expanding membership in Latin America, Mexico, Central and Eastern Europe, and Japan and Asia (ISPP, 1998). In 2000, it was decided that, in every "ten-year period, [the ISPP] will meet four times in North America, four times in Europe, and twice somewhere else in the world" (ISPP, 2000). Yet, by 2007 it was still the case that "about two-thirds of the membership of ISPP [was] from North America" (ISPP, 2007, p. 3.), only a marginal improvement in internationalization from the 2.2-to-1 ratio in 1998.

Around this time, more urgent calls for internationalization began to be made, "not as an 'add-on' but as 'a lens through which we interrogate everything we do"' (Reicher, 2008, p. 17). The ISPP responded by convening a standing committee on internationalization and by instituting several structural and operational changes (ISPP, 2010; Nesbit-Larking \& Kinnvall, 2011). Since then, annual meetings have been held in North America only one year out of three (ISPP, 2019b). Also, since at least 2012, ISPP subscription and annual meeting fees have been on a sliding-scale to make them more affordable for members and participants from poorer countries (ISPP, 2012).

These interventions were quite effective, as by 2017 fewer than half of ISPP members (44.1\%) and presenters (32.3\%) at the following Edinburgh conference were North American (Reynolds \& Yeow, 2018). However, despite substantial improvements in internationalization, less progress has been made in extending participation beyond North America and Europe: in 2017, most members were North American (44.2\%) or Western European (37.6\%), and just $18.3 \%$ of members were from the rest of the world (with $8.3 \%$ from 
Australia and New Zealand, and the Middle East, and only 10\% from Asia, South America and Africa) (Reynolds \& Yeow, 2018).

How does this compare to other similar organizations? The American Political Science Association (APSA) has similar aims and objectives to the ISPP, but without the clear constitutional vision of international participation (APSA, 2017). However, since at least 2004, APSA has had an International Committee responsive to calls by two successive APSA presidents for “'mutual de-parochialization' in our knowledge practices [through] .... closer interaction between American and non-American political scientists" (Varshney, 2004). These efforts have been fruitful, with international (i.e. non-American) APSA membership rising from 10\% in 2004 (Varshney, 2004) to about 25\% in 2016 (Breuning et al., 2018). Thus, in comparison, the ISPP, with $66 \%$ of members from beyond North America, clearly has much more international participation.

Despite the ISPP's evident progress in internationalization, Reynolds (2018) concluded in her recent ISPP presidential address, "there is more work to be done on diversity and internationalization [in the ISPP]" (p. 753). However, before we know what should be done, we first need to understand the nature of internationalization in the ISPP's current activities. The present study uses bibliometric co-authorship analysis to assess the extent to which the Society is achieving its core goal of international collaboration in its two primary dissemination activities, namely its annual meetings and this journal, Political Psychology. We particularly explore how authors from different regions of the world are interconnected in the co-authorship network and whether the types of internationalization observed are likely to be creating the benefits envisaged in the Society's constitution.

\section{Academic Internationalization}

Academic collaborations forge links between individuals and institutions. There are many benefits, including the transfer of knowledge, skills, and resources - particularly when partners are from different countries and bring different paradigms, methods and expertise to the research (Katz \& Martin, 1997). However, a more important goal of internationalization in 
research is to develop models and theories that have relevance beyond their own historical and cultural milieu. Even within the positivistic epistemology predominant in North American political psychology, there are advantages to internationalization related to sampling and generalization. However, more profound advantages may be gained by extending the variety of epistemological perspectives visible to the 'mainstream' of the discipline (Nesbitt-Larking \& Kinnvall, 2014; de Sousa Santos, 2016).

\section{The Positivistic Imperative for Internationalization}

Most studies employ sampling logic by which small samples are assumed to be representative of the "general population," allowing results observed in a study to be assumed to have global significance (Hatemi \& McDermott, 2012). However, most studies are undertaken in Western, Educated, Industrialised, Rich, and Democratic (WEIRD) countries (Henrich, Heine, \& Norenzayan, 2010), with samples unrepresentative of the global population, particularly when considered historically. For instance, an analysis of top journals from six different sub-disciplines of psychology showed that approximately $68 \%$ of participants were from the United States, and 96\% of them were from WEIRD countries (Arnett, 2008). With respect to authorship, $73 \%$ of first authors were from US universities and $99 \%$ of all authors were from WEIRD countries. These findings present a situation where $99 \%$ of authors and $96 \%$ of samples used in the top six psychological journals come from countries with only around $12 \%$ of the world's population (Arnett, 2008).

While Henrich and colleagues (2010) and others have mainly explored the impact of WEIRD authors and samples in general psychology, its importance to political psychology and political science is increasingly being recognised in disciplinary literature (e.g. Alper \& Yilmaz, 2019; Eveland, Song, \& Beck, 2015; Onraet, Van Assche, Roets, Haesevoets, \& Van Hiel, 2016; Osborne, Sengupta, \& Sibley, 2018). Of course, this quite recent recognition by the academic "core" of the importance of non-WEIRD perspectives has long been acknowledged by those on the periphery (e.g. Ardila, 1996)! 
The predominance of "WEIRD" research is important, since there are profound differences between WEIRD and non-WEIRD nations in culture, income, education, and health that influence every aspect of psychological and political functioning (Arnett, 2008). Given that they constitute a relatively small proportion of the global population, theories and models developed with WEIRD samples can be strikingly unrepresentative of humanity at large, despite having the appearance of replicability in the academic literature (Henrich et al., 2010). The over-representation of WEIRD samples in research should limit our confidence in theoretical models (since the true population variability is under-represented in research and therefore invisible to theorists) and our ability to confidently generalize knowledge across geographical and historical contexts (since it is not demonstrated that models are crossculturally robust). In practice, however, results are often assumed to be universally generalizable despite their distinctive provenance (Sue, 1999). Something crucial is lost when leaving out such a large proportion of the human population, perhaps something with the potential to revolutionise current theories and paradigms (Arnett, 2008).

\section{Internationalization and Epistemological Diversification}

Frequently, the justification for including non-WEIRD samples in research is to test whether models and theories developed in WEIRD contexts generalize elsewhere. These models are developed with particular presuppositions about the nature of psychology and political processes (Mkhize, 2004). This process of developing theories and uncritically deploying them in other contexts can be a form of epistemological globalization that progressively erases local understandings and forms of knowledge (de Sousa Santos, 2006). Internationalization that only uncritically tests WEIRD theories in non-WEIRD contexts to see if they are "universal" will never see beyond its own horizons (de Sousa Santos, 2006).

Conversely, giving voice to diverse epistemological perspectives can facilitate a twoway flow of knowledge and perspectives between WEIRD and non-WEIRD researchers or, as de Sousa Santos puts it, establish "the capacity to learn from the experiences of the world" (2016, p. 19). Internationalization is therefore important for international academic societies 
like the ISPP, both to understand the limits of existing theories and models, and to enrich the discipline with perspectives from different cultures and settings.

\section{Internationalization and Power}

Parochial social science has distinct limitations, as discussed. However, thoughtless internationalization may be just as bad, as it can result in intellectual colonialization in which local perspectives are inhibited or displaced by imported paradigms (de Sousa Santos, 2016; Murphy \& Zhu, 2012). De Sousa Santos calls this epistemicide, and this might result from current replication projects in psychology. The net result can be a reduction in the global diversity of approaches, paradigms and perspectives, particularly when internationalization is confused for international reach.

To distinguish between internationalization-as-neocolonialism and less negative versions, we need to carefully consider the relationships between authors and the way that knowledge flows in systems of collaboration and dissemination. It is often useful here to distinguish between core (usually WEIRD) and periphery (usually non-WEIRD) countries (Newman, 2001; Schubert \& Sooryamoorthy, 2010). Most international academic collaboration occurs between authors within a core of primarily North American and European countries, with much less collaboration with and between countries in the academic periphery.

Alatas (2003) argues that even when core-periphery collaboration occurs, there is often an imbalance of power, on multiple dimensions. First, there is frequently a division between theoretical and empirical intellectual labour, with collaborators in academic core countries developing theory, setting research agendas and obtaining grants, while those in the periphery import theory and collect data. This is especially common in large multi-author studies, where periphery authors are tasked with funneling data back to authors at the core (Alatas, 2003).

Second, there is an asymmetry in the ability of core and periphery authors to undertake own-country and other-country studies (Alatas, 2003). Authors at the core focus on both core countries and periphery countries, but authors in periphery countries seldom independently 
study core countries. Alatas (2003) asserts that WEIRD scientific "power countries" have access to peripheral non-WEIRD countries, allowing for comparative research to be undertaken. In contrast, non-WEIRD countries are generally limited to empirical data-gathering and undertaking research only in their own countries.

We can illustrate this by comparing India (periphery) and the UK (core). A search of the Clarivate Analytics database (formerly IS) for papers with "India" and "UK" (or any of its constituent countries) in the title showed that while $6.66 \%$ of papers about India have corresponding authors with addresses in the UK, only $0.16 \%$ of papers about the UK have corresponding authors with addresses in India, despite India dwarfing the UK in size. This demonstrates the general rule that the "core" studies the "periphery", not vice versa. Consequently, social and psychological phenomena in periphery countries are frequently interpreted using theoretical and cultural paradigms developed by, and appropriate to, WEIRD countries, while core countries are most often studied on their own terms (Alatas, 2003.).

Thus, while internationalization is a worthy goal, it is important to differentiate between different types of internationalization and consider the types of collaborations that might achieve valuable (or harmful) outcomes (Van Den Besselaar, Inzelt, Reale, Turckheim, \& Vercesi, 2012). In the present co-authorship analysis, we distinguish between "nominal internationalization," where collaborations are between authors from different WEIRD countries, and "deep internationalization," where collaborations are between authors from both WEIRD and non-WEIRD countries, or between different non-WEIRD countries on the academic periphery. Deep internationalization is rare (Arnett, 2008).

The ISPP has consistently taken stock of its activities, influence, and trajectory. In this respect, it is particularly useful to "construct spatial maps of the field and, in particular, to trace origins, development and sway of the field across different countries and regions" (Nesbitt-Larking \& Kinnvall, 2011, p. 45). The present study follows this tradition by attempting to map the international footprint of the ISPP, using social network maps of 
relationships between co-authors in the two major Society activities: the journal Political Psychology and the annual meeting. The specific aim is to consider empirically the extent to which the ISPP is successfully achieving its constitutional aim of internationalization (ISPP, 2015).

\section{General Method}

Two sub-studies are reported. Study 1 mapped the activities of the ISPP journal Political Psychology from 1985 to 2014 (30 years). Study 2 mapped the co-authorship relationships at annual meetings from 2006 to 2014 (eight years). We will first describe the aspects of method common to both analyses and then report on each sub-study.

\section{Indexing Author Country Affiliation as WEIRD or non-WEIRD}

Author affiliation was extracted from bibliographic records (Study 1) or annual meeting programs or abstract booklets (Study 2). Overall, across the activities of the journal and annual meetings, 79 countries were represented. Country affiliation was categorized as WEIRD or non-WEIRD as described below.

Following Henrich et al. (2010), nations are categorized as WEIRD if they are Westernised, Educated, Industrialised, Rich, and Democratic. Countries that meet some of these requirements, but not all, are classified as non-WEIRD. It is recognized that there are countries that do not fall neatly into these classifications, but for the purpose of this research, only these two broad categories were used.

The initial source for indexing the countries as WEIRD or non-WEIRD nations was the United Nations Regional Group list (UNAIDS, 2014). The United Nations officially divided its member nations into five geopolitical groups: the African group; the Asia-Pacific group; the Eastern European group; the Latin American and Caribbean Group; and lastly, the Western European and Others group. The last group, the Western European and Others group, has territory dispersed on all of the continents. Although it is mostly centred in Western Europe and North America, Australia and New Zealand are part of this group as they are culturally and 
politically similar, despite being geographically distant. The United States of America is part of this group as an "observer" only.

The country classification index was then cross-checked with Organisation for Economic Co-operation and Development (OECD) membership. The OECD is an international economic organisation with 34 member countries committed to democracy and the market economy (OECD, 2016). Additionally, these 34 member countries were crosschecked against the World Bank's classification of "high-income OECD members" (World

Bank, 2014). Countries in both the 'Western European and Others' group of the United Nations Regional Group list, as well as having OECD membership, were considered WEIRD. These were: Australia; Austria; Belgium; Canada; Denmark; Finland; France; Germany; Greece; Iceland; Ireland; Israel; Italy; Luxembourg; Malta; Netherlands; New Zealand; Norway; Portugal; Spain; Sweden; Switzerland; Turkey; United States; and the United Kingdom. Those which met only some of the criteria, or none, were considered non-WEIRD. We acknowledge that some of these categorizations are less prototypical than others, but we chose to accept the internationally recognized groupings rather than making ad hoc determinations ourselves.

A custom script written by the authors (Quayle \& Greer, 2014) was customized to step through bibliographic data and categorize author's countries as WEIRD or non-WEIRD by matching the available address information on these criteria, and to save author collaborations as social network data. Where authors had multiple affiliations, the most recent non-WEIRD affiliation or, if no non-WEIRD affiliation existed, the most recent affiliation was recorded as canonical. Thus, authors were classified as non-WEIRD if they had published from a nonWEIRD affiliation even once. Visone (Baur et al., 2001) was used to visualize the co-authorship networks and calculate network metrics; these were then exported to SPSS for further analysis. 


\section{Network Analysis and Metrics}

Several social network metrics were calculated to describe and characterize the coauthorship networks.

Distance. The geodesic distance between two nodes (authors) is the minimum number of 'hops' that it takes to go from one author to another in the network. Those actors who are closer to others may be able to exert more influence (i.e. have more power) than those who are more distant. Distance relates to social capital, for example, in the ability to locate potential collaborators (or be located) via existing connections. For example, an author (A) who has a geodesic distance of one has a direct line of communication, via collaboration, with author (B), while an author (C) with a geodesic distance of two will be required to go through author (A) to collaborate with author (B). Specifically, we calculated the network distance between each author and the nearest non-WEIRD author. Authors with no connection to any non-WEIRD author were coded with a distance of zero and classified as missing data in further analysis.

Centrality. Centrality quantifies the influence or prominence of nodes in a network (Newman, 2010). Degree centrality is simply the sum of a node's ties (in this case, coauthorship relationships). Nodes (i.e. authors, in this research) with higher degree centrality (i.e. with more ties to other nodes) may be in a more advantaged position in the network. As these nodes have many ties, they have many routes on the network for social capital (e.g. knowledge flow; initiating collaborations), whilst those nodes which have lower degree centrality would have access to fewer partners for flows of information, future collaboration opportunities, and so on (Newman, 2010).

Closeness centrality is the mean geodesic distance from a given node to each other node in the network. The more central a node is, the lower its mean distance to all other nodes; thus, the lower an author's closeness centrality score, the better the author's position in the network. Closeness centrality describes the extent of the influence of a node on the network $(\mathrm{Ni}$, Sugimoto, \& Jiang, 2011). 
Betweenness centrality quantifies the number of times a node is included on the shortest paths between all other nodes. Nodes which have high betweenness values are on a large proportion of the possible shortest distances between nodes in the network. They are deemed to have considerable influence within a network due to the fact that they are exposed to, and often have a large amount of control over, information passing between other nodes (Newman, 2010). The current research used percentages for the centrality calculations, which normalizes the raw centrality value so that the centrality values of all nodes sum up to $100 \%$.

Since many of these metrics are not normally distributed and/or subject to strong floor effects, we have used non-parametric statistics where necessary. Note that there is limited value in understanding these statistics inferentially as the population is unclear; instead, they should be interpreted as an indication of how frequently effects this large or larger would be likely to be observed with random samples.

\section{Study 1: Internationalization in the journal, Political Psychology}

\section{Method and Procedure}

Bibliometric data was downloaded from the Thomson Reuters Web of Knowledge (WoK; previously ISI and now Clarivate Web of Science) for every article published in Political Psychology from its first coverage in the database (1985) to the time that data collection was undertaken (2014); this covers 30 years of publications. Raw data were cleaned and processed using the 'Science of Science ( $\left.\mathrm{Sci}^{2}\right)$ Tool' (Sci2-Team, 2009). This tool converted the WoK bibliographic records to an Excel table. Our custom script extracted author countries and generated a social network from co-authorship information. A total of 991 multiauthor papers and 160 single-author papers were processed.

\section{Results}

Including single-author papers, a total of 42 unique countries were represented; 24 of these were WEIRD, and 18 were non-WEIRD (see Table 1). Of all the unique authors $(N=1,151), 1088(94.5 \%)$ were affiliated with WEIRD nations while only $63(5.5 \%)$ were affiliated with non-WEIRD nations. 


\section{TABLE 1 ABOUT HERE}

A breakdown of authors by country (Table 1) shows that the United States was by far the most represented country, accounting for $62.7 \%$ of all unique authors. By contrast, all nonWEIRD countries combined account for just 5.5\% of all authors. By continent, North America accounted for the most authors $(n=771 ; 67 \%)$, followed by Europe $(n=251 ; 22 \%$; comprised of WEIRD Europe with $20.2 \%$ of all authors, and non-WEIRD Europe with $1.8 \%)$, Asia $(n=77 ; 6.7 \%)$, Australia (Oceania) $(n=27 ; 2.3 \%)$; Africa $(n=7 ; 0.6 \%)$, and South America $(n=7 ; 0.6 \%)$.

Since many authors contributed multiple papers during the sampling period we also considered total author representation. Here, the proportion of WEIRD to non-WEIRD representation was calculated by dividing the number of times non-WEIRD authors were represented each year in the time range by the total author count for that year. Overall representation of non-WEIRD countries $(6.1 \%)$ was similar to the proportion of unique authors from non-WEIRD countries (5.5\%) considered above.

The proportion of non-WEIRD representation was plotted longitudinally (see Figure 1). Non-WEIRD representation was absent in the first decade, peaked in the 1990's at about an eighth of total representation, and stabilized between about $2 \%$ and $8 \%$ from the late 1990 s to 2014 (Figure 1).

FIGURE 1 ABOUT HERE

Of 1,337 co-authorship ties, 419 crossed international boundaries. An "N-1" Chisquare test (Campbell, 2007) was used to compare the proportion of homogeneous country 
collaborations between WEIRD (proportion $=0.7 ; S D=0.46)$ and non-WEIRD (proportion $=$ $0.47 ; S D=0.5)$ authors. WEIRD authors had a significantly higher proportion of homogenous country collaboration $\left(X^{2}(1)=13.71 ; p<.001\right)$, which is partly driven by the large proportion of authors from a single country (USA).

In terms of distance between WEIRD and non-WEIRD authors, there were 928 instances where no path existed at all (see Table 2). Of the remainder, 17.2\% of WEIRD authors had between one and five hops before they were able to reach a non-WEIRD author in the network $(M=2.148$, median $=2, S D=1.04$, range $=4)$. A slightly higher proportion $(25.4 \%)$ of non-WEIRD authors had between one and four hops before they were able to reach a noncompatriot non-WEIRD author in the network $(M=2.25$, median $=2, S D=.856$, range $=3)$. Neither group was significantly closer to non-compatriot non-WEIRD authors (Mann-Whitney $U=1338, Z=-.595, p=.552, r=0.086)$.

These results indicate that, of the WEIRD authors included in the network, $17.2 \%$ had either a direct (one hop) or indirect (two-five hops) connection to a non-WEIRD author. The number of hops represent the number of nodes (i.e. authors) which must be traversed to reach a non-WEIRD author. Conversely, just over a quarter of non-WEIRD authors had a direct or indirect connection to another non-WEIRD author of a different national affiliation. The mean number of hops required to reach a non-WEIRD author was not significantly different for WEIRD and non-WEIRD nodes.

\section{TABLE 2 ABOUT HERE}

While there are several large groups of connected authors, there was no core interconnected community of academics publishing in the journal. Excluding single author isolates, there were 255 connected components (i.e. collaboration groups) in the coauthorship network, with an average of 2.896 nodes in each component. The largest component consisted 
of 36 authors; most collaboration groups were small and disconnected. Only three of these collaboration groups included more than one non-WEIRD author.

For centrality, independent sample $t$-tests were used to compare the centrality of WEIRD and non-WEIRD authors (Table 3) within the co-authorship network (which excluded single-author papers). The results show that there was no significant difference between WEIRD and non-WEIRD authors in terms of all three measures of centrality: 1) the number of authors to whom they are directly connected (degree centrality), 2) the number of nodes to which they are connected, both directly and indirectly (closeness centrality), and 3) the number of times a node connects other nodes by inclusion in the shortest path between them (betweenness centrality). While centrality metrics are of limited utility in such a fragmented network, we note that WEIRD authors had significantly higher closeness centrality than nonWEIRD authors.

\section{TABLE 3 ABOUT HERE}

For author status, with regard to the average number of co-authors in a paper, WEIRD authors $(M=2.77 ; S D=1.44)$ tended to publish in smaller groups than non-WEIRD authors $(M=3.7 ; S D=1.78), t(1149)=4.874 ; \mathrm{p}<0.001 ; d=0.632)$ and on average were more likely to be listed as corresponding author $(M=.484 ; S D=.47$; Median $=.5)$ than non-WEIRD authors $(M=.281 ; S D=.43$; Median $=0$; Mann-Whitney $U=24187.5, Z=-3.196, p=.001)$.

Average author position (first author, second author, etc.) was calculated for each author across their publications. For the purpose of this analysis, the author position status was ranked, with the first-author position being most important and last-author least. While in some disciplines the last author is often considered to have more status than middle authors, this distinction is less reliable than first-authorship and is ignored in this analysis. Since these distributions are by definition positively skewed (with all papers having a first author, but the frequency of papers having authors in each consecutive position falling off sharply), a 
nonparametric test was used. Author position differed significantly for WEIRD $(M=1.91, S D$ $=1.13$, median $=2$, range $=10)$ and non-WEIRD $(M=2.55, S D=1.46$, median $=2$, range $=6)$ authors $(U=23765.5 ; Z=-4.08 ; p<0.001 ; r=0.286)$, with WEIRD authors more likely to have higher (closer to first) author positions when compared to their non-WEIRD counterparts.

However, since this difference is partly a function of WEIRD authors publishing in smaller groups and therefore having lower maximum positions, we also calculated an author position index by dividing the author position by the number of collaborating authors. The mean author position index for WEIRD $(M=.735$, median $=.75, S D=.264$, range $=1)$ and non-WEIRD $(M=.728$, median $=.75, S D=.274$, range $=.75)$ authors did not differ significantly $(U=33643 ; Z=-.255 ; p=.798 ; r=0.018)$. It must be left to the reader to decide whether being second of two authors is of higher status than being the third of three (as in the first analysis) or equivalent (as in the second).

\section{Study 2: Internationalization in ISPP conference abstracts}

\section{Methods}

Similar methods were used to map the co-authorship network from abstracts presented at the annual ISPP conference, using conference programs posted on the ISPP website and programs on file in the ISPP Central Office. One year's programs were not on file, and these were requested and received from the program chair for that year. The timeframe for the bibliometric data used in this research was the years 2006-2014, which was determined by the availability of records at the time data collection commenced. It was not always possible to determine an author's country of affiliation from the address or email given on the conference program, and these authors are retained in the network with no country affiliation.

We did not compare authorship position for conference presentations, as it is not clear that authors use the same procedures for determining authorship for conference papers as for 
journal publications. Also, we did not differentiate between papers presented in panels and those submitted as stand-alone presentations.

\section{Results}

In terms of WEIRD vs non-WEIRD author differences, a total of 4,260 unique authors from 74 countries were listed on papers presented at the ISPP annual meetings. Of these, 3,675 $(86.13 \%)$ listed WEIRD country affiliations, 523 (12.23\%) listed non-WEIRD affiliations, and $70(1.64 \%)$ did not specify their country of affiliation. Table 4 shows the affiliated country count and overall percentage of unique authors who published within the journal. In contrast to the journal results, more unique non-WEIRD $(n=51)$ countries were represented than WEIRD $(n=23)$. However, 13 countries had only a single representative, while a further eight countries had two representatives each. As in the journal, the USA was still the most frequently represented country $(37.6 \%)$, but the distribution was flatter with a much longer tail.

The sample included many sole authors $(N=1,151)$ who presented single-author papers (WEIRD: $N=920,25 \%$ of WEIRD; non-WEIRD: $N=202,38.8 \%$ of non-WEIRD). These single authors were predominantly from North America $(N=431,37.44 \%)$, Western Europe $(N=329,28.58 \%)$, and the Middle East $(N=140,12.16 \%$; primarily Israel: $N=108,9.38 \%)$, with the rest from Eastern Europe $(N=89,7.73 \%)$, South Central America $(N=56$, $4.87 \%)$, Asia $(N=31,2.35 \%)$, Australia $(N=27,2.35 \%)$, and Africa $(N=19,1.65 \%)$.

There were 3,109 authors who contributed multi-author papers and could be included in the co-authorship analysis. Of these, 2,749 (88.42\%) authors were from WEIRD countries and $319(10.26 \%)$ from non-WEIRD countries, with the remainder not specifying their country of affiliation. Most authors were from North America $(N=1,521,48.92 \%)$ followed by Western Europe $(N=1,122,36.08 \%)$; the Middle East $(N=270,8.68 \%$; primarily Israel, $N=198$, $6.37 \%)$, Eastern Europe $(N=180,5.79 \%)$, South Central America $(N=103$, $3.31 \%)$, Australasia $(N=71,2.28 \%)$, Asia $(N=46,1.48 \%)$, and Africa $(N=25,0.8 \%)$. 


\section{TABLE 4 ABOUT HERE}

Of 6,884 co-authorship ties, 1,884 were international collaborations. An "N-1" Chisquare test (Campbell, 2007) compared the proportion of homogeneous country collaborations between WEIRD (proportion $=0.81, S D=0.32)$ and non-WEIRD $($ proportion $=0.75, S D=$ 0.38) authors. There was no significant difference in proportion of homogenous country collaboration $\left(\chi^{2}(1)=.016, \mathrm{p}=.900\right)$.

In terms of distance, the isolates which did not have bibliometric data $(n=70)$ were excluded from the distance analysis. There were 2,701 instances where no path existed at all, and distance was coded as missing. This left $37.5 \%$ of WEIRD authors with between one and eight hops to non-WEIRD authors in the network $(M=2.97$, median $=3, S D=1.442$, range $=$ 7). For non-WEIRD authors, $29.4 \%$ were able to reach non-compatriot non-WEIRD authors in the network with between one and six hops $(M=2.58$, median $=3, S D=1.092$, range $=5)$. The count and percentage of the distance for each number of 'hops' is displayed in Table 5. Network distance is usually positively skewed so a Mann-Whitney U test was used to test whether WEIRD authors were significantly more likely to be closer to non-WEIRD authors than non-compatriot non-WEIRD authors were. This difference was significant $(U=91247.5$, $z=-2.794, p=.005, r=0.134)$. This suggests that non-WEIRD authors who did have a connection to other non-compatriot non-WEIRD authors had less distance to cross to reach them on the network, compared to WEIRD authors.

This finding highlights that, in the conference proceedings, $37.5 \%$ of WEIRD authors had a direct (one hop) or indirect (two to eight hop) connection to a non-WEIRD author, while just under $30 \%$ of non-WEIRD authors had a direct or indirect connection to other nonWEIRD authors from different countries. The mean number of nodes that needed to be crossed to reach a non-WEIRD author in the co-authorship network was significantly higher for WEIRD authors than non-WEIRD authors. 


\section{TABLE 5 ABOUT HERE}

When mapping the authorship network of the conference abstracts, it was found that one giant component existed $(N=1,430)$, alongside other, much smaller, clusters of authors. Excluding single-author isolates, there were a total of 506 connected components in the coauthorship network, with an average of 4.428 nodes in each component. In this network, $89.1 \%$ of the authors were affiliated with WEIRD countries, while $9.1 \%$ were affiliated with nonWEIRD countries. Additionally, WEIRD authors displayed more within-group collaboration than non-WEIRD authors.

The fact that a giant component emerges suggests that the annual meetings are producing an interconnected community of scholars to a greater extent than the activities of the journal, although it should be noted that giant components emerge partly as a function of network scale (Strogatz, 2001), and the annual meeting network is substantially larger than the journal network.

Even in the giant component, collaboration between WEIRD $(N=1,275,89.1 \%)$ and non-WEIRD authors $(N=131,9.1 \%)$ is limited. There were 5,812 $(69.9 \%)$ WEIRD-WEIRD links between authors in the network overall, with 4,023 (84.3\%) in the giant component. In contrast, there were $426(6.1 \%)$ links between non-WEIRD authors in the network and 285 $(5.8 \%)$ in the giant component, with $646(9.3 \%)$ links between WEIRD and non-WEIRD authors in the network and $535(11.0 \%)$ in the giant component.

In terms of centrality. There was a significant difference in betweenness $(U=$ $416010.5, Z=-1.970, p=0.049, r=0.051)$ between WEIRD $(M=.033$, median $=0, S D=$ .189 , range $=5.63)$ and non-WEIRD authors $(M=.014$, median $=0, S D=.065$, range $=.66)$. There was a significant difference in mean degree percentage between WEIRD $(M=.032$, median $=.02, S D=0.054$, range $=.93)$ and non-WEIRD $(M=0.03$, median $=.02, S D=0.49$, range $=.48)$ authors $(\mathrm{U}=394980, \mathrm{Z}=-2.962, p=0.003, r=0.1)$. Additionally, there was a significant difference in mean closeness percentage between WEIRD $(M=.032$, median $=.002$, 
$S D=.035$, range $=.11)$ and non-WEIRD $(M=.029$, median $=0, S D=0.034$, range $=.09)$ authors $(U=387478, \mathrm{Z}=-3.414, p=0.001, r=0.182)$. Overall, these outcomes paint a picture which suggests that there are substantial differences in network position between WEIRD and non-WEIRD authors in this medium.

The proportion of non-WEIRD representation was plotted longitudinally (see Figure 2). International representation ranged between $6 \%$ and $12 \%$ during the time period, with no clear upward or downward trend, except that meetings in the USA tended to have lower internationalization.

FIGURE 2 ABOUT HERE

\section{Discussion}

The present study continues a small tradition exploring the state of the field of political psychology globally; this focus seems to have declined since the early 2000's. As

Suedfeld (2006) noted around that time, simply searching for papers titled "political psychology in ...." yielded papers on the state of the field in many countries and regions, including Japan (Feldman, 1997), the Philippines (Montiel, \& Chiongbian, 1991), Israel (BarTal, 1988), Canada (Nesbitt-Larking, 2004), China (Shumao, 1996), New Zealand (Lamare, \& Milburn, 1990) and others. Our studies aimed to explore the extent and character of internationalization in the core dissemination activities of the ISPP.

Overall, our results show that the activities of the ISPP have high levels of internationalization, with the journal and annual meetings combined representing authors from 79 unique countries (approximately two-fifths of the countries of the world). However, there is an extreme positive skew to the distribution of representation, with most authors representing just a few countries. 
The ISPP's journal Political Psychology primarily represents the work of WEIRD authors. North America was by far the most frequently represented region, followed by Western Europe. This result is in line with the general argument that the bulk of psychological research and practices originate from WEIRD countries, and particularly from the United States (Henrich et al., 2010; Sue, 1999). When only collaborative papers were considered, there was a more even spread of authors between North America and Western Europe. However, overall, non-WEIRD authors were dramatically under-represented compared to WEIRD authors, and work from North America and Western Europe dominated the publication.

While similar patterns were observed at annual meetings, a much broader spread of countries was represented, and the dominance of North America and Europe was less pronounced. Generally, a higher proportion of authors at annual meetings were from nonWEIRD countries (particularly when the venue was not in the USA), and there was more collaboration (in absolute and relative terms) between WEIRD and non-WEIRD authors at annual meetings than in the journal.

The differences in the proportion of WEIRD to non-WEIRD authors between the journal and the annual meetings may also be reflective of different eras in the Society's history. For instance, the journal started off with no non-WEIRD author publications at all for the first two years (1985-1987), while a tenth of the authors presenting abstracts in the first year the annual meetings were assessed (2006) were non-WEIRD.

In both networks, international collaborations were the exception, not the norm. This is hardly surprising, as local (perhaps even within the same department) and national collaborations are much more practical than international ones, particularly for people from very large countries such as the USA. Thus, in both networks, WEIRD authors were more likely to publish together, partly due to the simple fact that more authors are available for collaboration in WEIRD than in non-WEIRD countries. For example, there are more internationally publishing social psychologists in a tiny country like Norway than in the entire continent of Africa (Quayle \& Greer, 2014). 
In both networks, however, the majority of authors were not socially connected to any non-WEIRD authors in the collaboration network by any route (i.e. they could not reach a noncompatriot non-WEIRD author via the network of co-authors to whom they were connected). However, the patterns of connection differed across networks.

In the journal authorship network, more WEIRD authors had collaborative ties to noncompatriot non-WEIRD authors than non-WEIRD authors did. Put more simply, authors from less-developed countries are more distant from non-compatriot non-WEIRD authors than authors from developed countries. This pattern is consistent with the hub-and-spoke patterns of collaboration that often develop between core and periphery countries (Boshoff, 2009; Quayle $\&$ Greer, 2014). In these collaboration systems, developed countries frequently act as intermediaries, with authors from different non-WEIRD countries connected together primarily via hubs in WEIRD countries. Indeed, in the journal network only three nonWEIRD authors had direct collaborations with non-compatriot non-WEIRD authors. Importantly, WEIRD authors were perhaps more likely to have author precedence, have fewer authors involved in projects, and were more likely to be the corresponding author. These hub-and-spoke links are frequently forged through interventions like scholarship programs and international aid initiatives, and therefore frequently embed power imbalances in favour of WEIRD authors (Alatas, 2003).

This pattern was different in the annual meetings. While the proportion of authors with any connection to non-WEIRD authors was still relatively low, more non-WEIRD authors had connections to non-compatriot non-WEIRD authors than WEIRD authors did, and distances to non-WEIRD authors were generally lower. However, only $6.1 \%$ of nonWEIRD authors collaborated with other non-WEIRD authors, and only a tenth of the links in the network included non-WEIRD authors.

The co-authorship network in the journal was relatively fragmented, with just a few connected groups of co-authors. Most authors represented were not tied into larger collaborative groups. In contrast, the annual meetings were characterised by a 'giant component' 
of connected collaborators, with numbers of integrated groups representing a much larger proportion of authors.

The relative fragmentation in the journal co-authorship is probably related to several things. First, as a high-impact peer-reviewed journal, it casts a wider net, publishing work well beyond the boundaries of the ISPP as a society. The annual meetings, by contrast, are much more likely to be attended by Society members and researchers with closer interests in the Society's goals and activities. Second, ISPP members publish in a wide variety of journals, meaning that many papers presented at the conference are likely to be published elsewhere (or nowhere). Third, giant connected components (i.e. including a large proportion of members of a network) are more likely to emerge as a network increases in size (Strogatz, 2001). Since the journal represents a subset of authors from the annual meetings (along with others who have never attended an ISPP annual meeting), it is possible that a similar giant component would emerge at sufficient scale. It is also possible, however, that the more tightly constrained selection procedures for the journal filter out the types of collaborative work that result in the connections between 'silos', as evident in the giant component of connected authors at the annual meetings.

The measures of centrality that were used in the analysis of both the journal and annual meetings allow us to consider the position and power of WEIRD and non-WEIRD authors in the authorship networks. In the journal, there were no significant differences between WEIRD and non-WEIRD authors for degree closeness (showing that they are not significantly more likely to have many more co-authors) or betweenness centrality (showing that are not more likely to fall on closest paths between other authors). However, WEIRD authors had significantly lower closeness scores, which shows in this sense they are situated at the 'core' of the network and are more accessible to other authors (Newman, 2001; Schubert \& Sooryamoorthy, 2010). In the ISPP conference network, non-WEIRD authors are closer (in social network terms) to other (non-compatriot) non-WEIRD authors (the opposite pattern to Quayle \& Greer, 2014). While betweenness values between WEIRD and nonWEIRD authors 
were similar in both networks, WEIRD authors had significantly higher degree centrality values in the conference abstract network, indicating that on average they had more collaborators despite publishing in smaller groups per paper.

These network features are indicators of academic social capital (Alatas, 2003; Arnett, 2008). In both networks, in different ways, authors from WEIRD countries have more academic social capital. This capital is the basis for forging links with co-authors: if you are from a WEIRD country, you are better positioned to do so than if you are from a non-WEIRD country.

On balance, there are aspects of these findings that are impressive: the ISPP has provided a platform for authors from 79 countries. International collaborations are frequent and productive. Between the journal and the annual meetings, during the time periods analysed, the ISPP facilitated 2,320 international collaboration ties between authors. By any measure, these are valuable accomplishments.

However, the majority of these collaborations are exclusively between authors from WEIRD countries. Deep internationalization is still rare in the Society's core activities. NonWEIRD countries are infrequently represented; it is unusual for authors from WEIRD countries to collaborate with authors from non-WEIRD countries, and even rarer for authors from non-WEIRD countries to collaborate with colleagues from other (i.e. non-compatriot) non-WEIRD countries.

\section{Limitations}

At a general level, the activities of the ISPP provide a narrow lens on the discipline of political psychology. There is a great deal of political psychology being undertaken in other languages and other parts of the world (eg. Africa; Asia; South America) that is not well represented in ISPP activities and therefore invisible to the present analysis. Ironically, by only counting research published in a specific journal and conference, the present study is a good example of how WEIRD epistemological commitments can impose horizons that erase other forms of knowledge (de Sousa Santos, 2016). Further research would be needed to identify this 
work in the "periphery" and make it visible in the "core," for example, by undertaking a “snowball” sample starting with non-WEIRD ISPP members, or by searching "grey literature" for a broader range of voices in political psychology.

At a technical level, bibliometric research identifies authors by name and there is inconsistency in how names are recorded in the Thomson Reuters Web of Knowledge (WoK; previously ISI and now Clarivate Web of Science), particularly before and after the year 2007. Names are sometimes recorded in full, sometimes with multiple initials and sometimes with just one initial. Bibliometric analysis has to balance the risk of erroneously treating multiple works from the same author as having different authors (e.g. treating Smith, M. and

Smith, M. F. as two people), against the risk of accidentally assigning works by different authors to one entity. Since the surname + first-initial format is the lowest common denominator of the several formats that appear in the database, this is generally considered least problematic (Milojevic, 2013), but it carries the slight risk of combining two or more authors who share the same surname and first initial.

Also, an important feature of the global academy is that talented young people are drawn from the periphery to study in the core and then publish with their WEIRD university affiliations. An unknown number of non-WEIRD researchers (especially early-career researchers) are therefore miscategorized as WEIRD, if they publish only with WEIRD affiliations. This is an unavoidable feature of the data source; however, our algorithm tries to minimize it by coding an author as non-WEIRD if any address from any of their publications is a non-WEIRD institution. Additionally, this subset of miscategorized authors are usually coauthoring with supervisors and therefore subject to a power structure that would frequently limit the benefits of international cooperation (e.g. a two-way flow of information) (Glänzel \&Schubert, 2004; Alatas, 2003).

Lastly, the time period analysed only extends to 2014. This was determined by the availability of records at the time data collection commenced, but is a clear limitation as the pattern and extent of internationalization may have changed since then. 


\section{Conclusions and Recommendations}

We explored the level of 'internationalization' in the activities of the International Society for Political Psychology by investigating two of the Society's core activities, the journal Political Psychology and the annual conference. In both platforms, WEIRD - and particularly North American - authors predominate. In both activities, the results showed that while internationalization is generally increasing, there are relatively few collaborations between WEIRD and non-WEIRD authors or between non-WEIRD authors from different countries. So, while internationalization is occurring within ISPP dissemination activities, with some years and venues achieving more non-WEIRD author presence than others, "business as usual" is not achieving deep internationalization.

So what recommendations can be made? First, we acknowledge that the lens provided on political psychology in the present analysis is very narrow. While it tells us something about how periphery political science is entering the core, it says nothing about the work being done elsewhere. For this reason, we hope to see a revival of the metascience research that thrived in the late 1990's and early 2000's, describing political psychology in regions across the world.

Second, and perhaps most obviously, we hope that efforts to engage academics from the "periphery" are intensified in the activities of the journal Political Psychology and ISPP annual meetings. The present study shows that impressive gains have been made since the inception of the ISPP, but that more can be done to improve non-WEIRD representation and deep internationalization. There is certainly high-quality non-WEIRD research being published in other outlets (e.g. African Affairs; Revista Electrónica de Psicología Política; Asian Journal of Social Psychology; Asian Journal of Political Science, etc.). An easy first step would be to list these cognate journals in author instructions and encourage submissions to Political Psychology to cite non-WEIRD work where relevant. Creating a systematic incentive to create links "out" into global literature would demonstrate openness to global research that may result in greater visibility in non-WEIRD contexts. 
We also note that internationalization is much more evident at annual meetings than in the journal. Perhaps more could be done to spark international networking at annual meetings that might ultimately result in joint publications; however, there may already be many worthy papers presented at annual meetings that could ultimately be published in the Society's journal but are not. Given the uneven playing field in the global academy, perhaps authors writing from the periphery would benefit from additional support to get their papers from conference paper to publication in a top-tier journal? This would require systematic procedures for identifying candidate papers and providing mechanisms to support authors towards publication.

Third, we hope to encourage more research comparing political psychology phenomena across global contexts (e.g. O’Dwyer, \& Çoymak, 2019), especially when results and theories are compared and synthesized across multiple non-WEIRD contexts in the same paper; as we have shown, this is currently done very rarely indeed. This "deep internationalization" will likely realize more of the possible benefits of internationalization and is an important response to the "replication crisis" in the social sciences, this because it helps the discipline to distinguish between universal and local truths (cf. Henrich, Heine, \& Norenzayan, 2010). We suggest that resources and incentives could be provided to encourage this. As an example of resource allocation, the ISPP has been offering small grants for local meetings in non-WEIRD contexts (e.g. Koc, 2019), but might also consider explicitly supporting small-scale research collaborations between members in different non-WEIRD countries. As an example of structural incentives, papers with multi-country collaborations or data could be prioritized in editorial processes.

Fourth, future research may consider examining the impact of the acting editorial teams, which have a five-year tenure. Different editorial teams bring in different editorial policies which may have different priorities for internationalization; does this editorial policy play a role in the extent to which the ISPP facilitates the publication of internationalized research? 
Society now has members and contributors from across the globe and has truly global reach. However, as always, improvements can be made. We suggest that the next phase of internationalization in the ISPP should focus on "deep internationalization," to more fully realize the benefits that internationalization can bring. 


\section{References}

Alatas, S. F. (2003). Academic dependency and the global division of labour in the social sciences. Current Sociology, 51(6), 599-613.

Alper, S., \& Yilmaz, O. (2019). How is the Big Five related to moral and political convictions: The moderating role of the WEIRDness of the culture. Personality and Individual Differences, 145, 32-38. https://doi.org/10.1016/j.paid.2019.03.018

APSA. (2017). Bylaws of the Association of the American Political Science Association

$\begin{array}{llll}\text { (Effective } & \text { Summer } & \text { 2017). } & \text { Retrieved }\end{array}$ https://www.apsanet.org/Portals/54/goverance/APSA\%20Bylaws_2017.pdf?ver=2017 $-08-18-122510-007$

Ardila, R. (1996). Political psychology: The Latin American perspective. Political Psychology, 17(2), 339-351. https://doi.org/10.2307/3791814

Arnett, J. J. (2008). The neglected 95\%: Why American psychology needs to become less American. American Psychologist, 63(7), 602-614.

Bar-Tal, D. (1988). Political psychology in Israel. Political Psychology, 9(4), 737-742. https://doi.org/10.2307/3791543

Baur, M., Benkert, M., Brandes, U., Cornelsen, S., Gaertler, M., Köpf, B., . . Wagner, D. (2001). Visone software for visual social network analysis. Paper presented at the International Symposium on Graph Drawing. Retrieved from?

Bondarevskaya, I., \& Tkalych, M. (2010). Status of political psychology in Ukraine. Societal and Political Psychology International Review, 1(1), 133-144. Retrieved from https://ssrn.com/abstract=1971755

Boshoff, N. (2009). Neo-colonialism and research collaboration in Central Africa. Scientometrics, 81(2), 413-434. https://doi.org/10.1007/s11192-008-2211-8

Bozyk (2006).

Breuning et al (2018).

Campbell, I. (2007). Chi-squared and Fisher-Irwin tests of two-by-two tables with small sample recommendations. Statistics in Medicine, 26(19), 3661-3675. 
Chmyreva , V. (2015). Политическая психология в России: актуальные вопросы международных исследований [Political psychology in Russia: Topical issues of international research. RUDN University Journal: Series International Relations, $15(2), 135-142$.

Cottam, M., Dietz-Uhler, B., Mastors, E., \& Preston, T. (2010). Introduction to political psychology. New York, NY: Psychology Press de Sousa Santos, B. (2006).

Globalizations. Theory, Culture \& Society, 23(2-3), 393-399.

de Sousa Santos, B. (2016). Epistemologies of the South and the future. From the European South: A transdisciplinary journal of postcolonial humanities, 1, 17-29.

Enserink, M. (2018). Research on research. Science, 361(6408), 1178-1179. https://doi.org/10.1126/science.361.6408.1178

Eveland, W. P., Jr, Song, H., \& Beck, P. A. (2015). Cultural variations in the relationships among network political agreement, political discussion frequency, and voting turnout. International Journal of Public Opinion Research, 27, 461-480.

\section{https://doi.org/10.1093/ijpor/edv007}

Glänzel, W., \& Schubert, A. (2004). Analysing scientific networks through co-authorship. In H. F. Moed, W. Glänzel, \& U. Schmoch U. (Eds), Handbook of quantitative science and technology research (pp. 257-276). Dordrecht: Springer.

Hatemi, P. K., \& McDermott, R. (2012). Broadening political psychology. Political Psychology, 33(1), 11-25. doi:10.1111/j.1467-9221.2011.00867.x

Henrich, J., Heine, S. J., \& Norenzayan, A. (2010). Most people are not WEIRD. Nature, 466(7302), 29-29.

Huddy, L., Sears, D. O., \& Levy, J. S. (2013). Introduction: Theoretical foundations of political psychology. In L. Huddy, D. O. Sears, \& J. S. Levy (Eds.), The Oxford handbook of political psychology (pp. 1-19). New York, NY: Oxford University Press. https://doi.org/10.1093/oxfordhb/9780199760107.013.0001

Hur, D. U., \& Sabucedo, J. M. (2017). Psicologia Política no Brasil: análise bibliométrica sobre sua revista [Political Psychology in Brazil: Bibliometric analysis on its Journal]. 
Psicologia Política, 17(38), 7-34.

ISPP. (1998a). ISPP News - Spring 1998. Archived snapshot September 02, 2003. Retrieved from

https://web.archive.org/web/20030902223622/http://ispp.org:80/publications/ISPPNe wspdf/spring1998.pdf

ISPP. (1998b). ISPP News - Fall 1998. Archived snapshot March 11, 2004. Retrieved from https://web.archive.org/web/20040311223103/http://ispp.org:80/publications/ISPPNe $\underline{\text { wspdf/fall1998.pdf }}$

ISPP. (2000). ISPP News - Spring 2000. Archived snapshot March 11, 2004. Retrieved from https://web.archive.org/web/20060216062110/http://ispp.org:80/publications/ISPPne wspdf/spring2000.pdf

ISPP. (2007). ISPP News - Spring 2007. Archived snapshot June 23, 2007. Retrieved from https://web.archive.org/web/20070623232107/http://ispp.org/publications/ISPPnewsp df/ISPPSpring07newsletter.pdf

ISPP. (2010). ISPP News - Spring 2010. Archived snapshot September 21, 2011. Retrieved from https://web.archive.org/web/2011*/http://www.ispp.org/publications/ISPPnewspdf/IS PPspring2010newsletter-electronic.pdf

ISPP. (2012). ISPP membership pricing. Archived snapshot October 20, 2012. Retrieved from https://web.archive.org/web/20121020001253/https://www.ispp.org/membership/prici $\underline{n g}$

ISPP. (2015). Constitution of the International Society of Political Psychology. Retrieved from https://www.ispp.org/about/constitution

ISPP. (2019a). About ISPP. Retrieved May 22nd, 2019, from https://web.archive.org/web/20180809031808/http://www.ispp.org/about ISPP. (2019b). Past meetings. Retrieved May 23rd, 2019, from https://web.archive.org/web/20180814162107/http://www.ispp.org/meetings/pastKoc, Y. (2019, April 24). ISPP blog: On the Pacific meeting on the psychology of social 
change in Santiago, Chile. Retrieved from https://www.ispp.org/ecc/blog/onthepacific-meeting-on-the-psychology-of-social-change-in-santiago-chile

Katz, J. S., \& Martin, B. R. (1997). What is research collaboration? Research Policy, 26(1), $1-18$.

Lamare, J. W., \& Milburn, T. W. (1990). Political psychology in New Zealand. Political Psychology, 11(3), 607-616.

Milojevic, S. (2013). Accuracy of simple, initials-based methods for author name disambiguation. Journal of Informetrics, 7(4), 767-773.

https://doi.org/10.1016/j.joi.2013.06.006.

Mkhize, N. (2004). Psychology: An African perspective. In K. Ratele, N. Duncan, D. Hook, N. Mkhize, P. Kiguwa, \& A. Collins (Eds). Self, community \& psychology (pp. 4.14.29). Cape Town: UCT Press.

Montiel, C. J., \& Chiongbian, V. M. (1991). Political psychology in the Philippines. Political Psychology, 12(4), 759-777. https://doi.org/10.2307/3791556

Murphy, J., \& Zhu, J. (2012). Neo-colonialism in the academy? Anglo-American domination in management journals. Organization, 19(6), 915-927.

Nesbitt-Larking, P. (2004). Political psychology in Canada. Political Psychology, 25(1), $97-$

\section{4. https://doi.org/10.1111/j.1467-9221.2004.00358.x}

Nesbitt-Larking P. (2014). Ideology, society and the state: Global political psychology in retrospect. In P. Nesbitt-Larking, C. Kinnvall, T. Capelos, \& H. Dekker (Eds.), The Palgrave handbook of global political psychology. Palgrave Studies in Political Psychology Series. London: Palgrave Macmillan.

Nesbitt-Larking, P., \& Kinnvall, C. (2011). The discursive frames of political psychology. Political Psychology, 33(1), 45-59. https://doi.org/10.1111/j.1467-

9221.2011.00862.xNewman, M. (2010). Networks: An introduction. New York, NY: Oxford University Press.

Newman, M. E. (2001). The structure of scientific collaboration networks. Proceedings of the 
National Academy of Sciences, 98(2), 404-409.

Ni, Sugimoto \& Jiang (2011).

O’Dwyer, E., \& Çoymak, A. (2019). Basic human values and their contexts: A multilevel analysis of support for the use of armed drones in the United States, United Kingdom, and Turkey. Political Psychology. https://doi.org/10.1111/pops.12621

OECD. (2016). List of OECD member countries - Ratification of the convention on the $O E C D$. Retrieved from https://www.oecd.org > about > document > list-oecd$\underline{\text { member-countries }}$

Onraet, E., Van Assche, J., Roets, A., Haesevoets, T., \& Van Hiel, A. (2016). The happiness gap between conservatives and liberals depends on country-level threat. Social Psychological and Personality Science, 8(1), 11-19. doi:10.1177/1948550616662125 Osborne, D., Sengupta, N. K., \& Sibley, C. G. (2018). System justification theory at 25: Evaluating a paradigm shift in psychology and looking towards the future. British Journal of Social Psychology, 58(2), 340-361. doi:10.1111/bjso.12302

Perry, S. M. (2011). Political psychology in evaluation: A theoretical framework. New Directions for Evaluation, 131, 21-26. doi:10.1002/ev.373

Polo, L., Godoy, J. C., Imhoff, D., \& Brussino, S. (2014). Following the tracks of an emerging area: Bibliometric analysis of Latin American political psychology in the 2000-2010 period. Universitas Psychologica, 13(5), 2047-2057.

\section{https://doi.org/10.11144/javeriana.upsy13-5.ftea}

Quayle, M., \& Greer, M. (2014). Mapping the state of the field of social psychology in Africa and patterns of collaboration between African and international social psychologists. International Journal of Psychology, 49(6), 498-502.

Reicher, S. D. (2008). The challenge of internationalization for ISPP. ISPP News, 19(2), 1617.

Reynolds, K. J. (2018). Looking back, looking forward: ISPP at 40 and future directions for political psychology. Political Psychology, 39(4), 745-754. https://doi.org/10.1111/pops.12509 
Reynolds, K. J., \& Yeow, J. (2018). Where have we come from and where are we heading? The past and present state of the International Society of Political Psychology. Report Commissioned by ISPP Governing Council. Retrieved from??

Schubert, T., \& Sooryamoorthy, R. (2010). Can the centre-periphery model explain patterns of international scientific collaboration among threshold and industrialised countries? The case of South Africa and Germany. Scientometrics, 83(1), 181-203.

Sci2-Team. (2009). Science of Science (Sci2) Tool. Indiana University and SciTech Strategies. https://sci2.cns.iu.edu.

Shen, C-L. (2007). A review of researches on political psychology in China in the past 20 years. Teaching and Research, 41(1), 57-62.

Shumao, W. (1996). Political psychology in China. Political Psychology, 17(4), 779-782. doi: $10.2307 / 3792138$

Strogatz, S. H. (2001). Exploring complex networks. Nature, 410(6825), 268.

Sue, S. (1999). Science, ethnicity, and bias: Where have we gone wrong? American Psychologist, 54(12), 1070.

Suedfeld, P., \& Hansen, I. (2006). The many faces of international political psychology. In L. E. Shepherd (Ed.), Political psychology (pp. 63-87). Opladen and Farmington Hills: Barbara Budrich. doi:10.2307/j.ctvddzf9p.8

UNAIDS. (2014). Official UN list of regional groups. The governance handbook. Retrieved from https://www.unaids.org > JC1682_GovernanceHandbook_March2011_en

Van Den Besselaar, P., Inzelt, A., Reale, E., Turckheim, E., \& Vercesi, V. (2012). Indicators of internationalization for research institutions: A new approach. European Science Foundation. Retrieved from https://www.vandenbesselaar.net >_pdf > 2012 ESF

Varshney, A. (2004). International: Internationalization of APSA: Why? How? PS: Political Science and Politics, 37(3), 533-535. Retrieved from http://www.jstor.org/stable/4488887

Wahutu, J. S. (2017). Representations of Africa in African media: The case of the Darfur violence. African Affairs, 117(466), 44-61. https://doi.org/10.1093/afraf/adx039 
World Bank (2014).

\section{FIGURES}

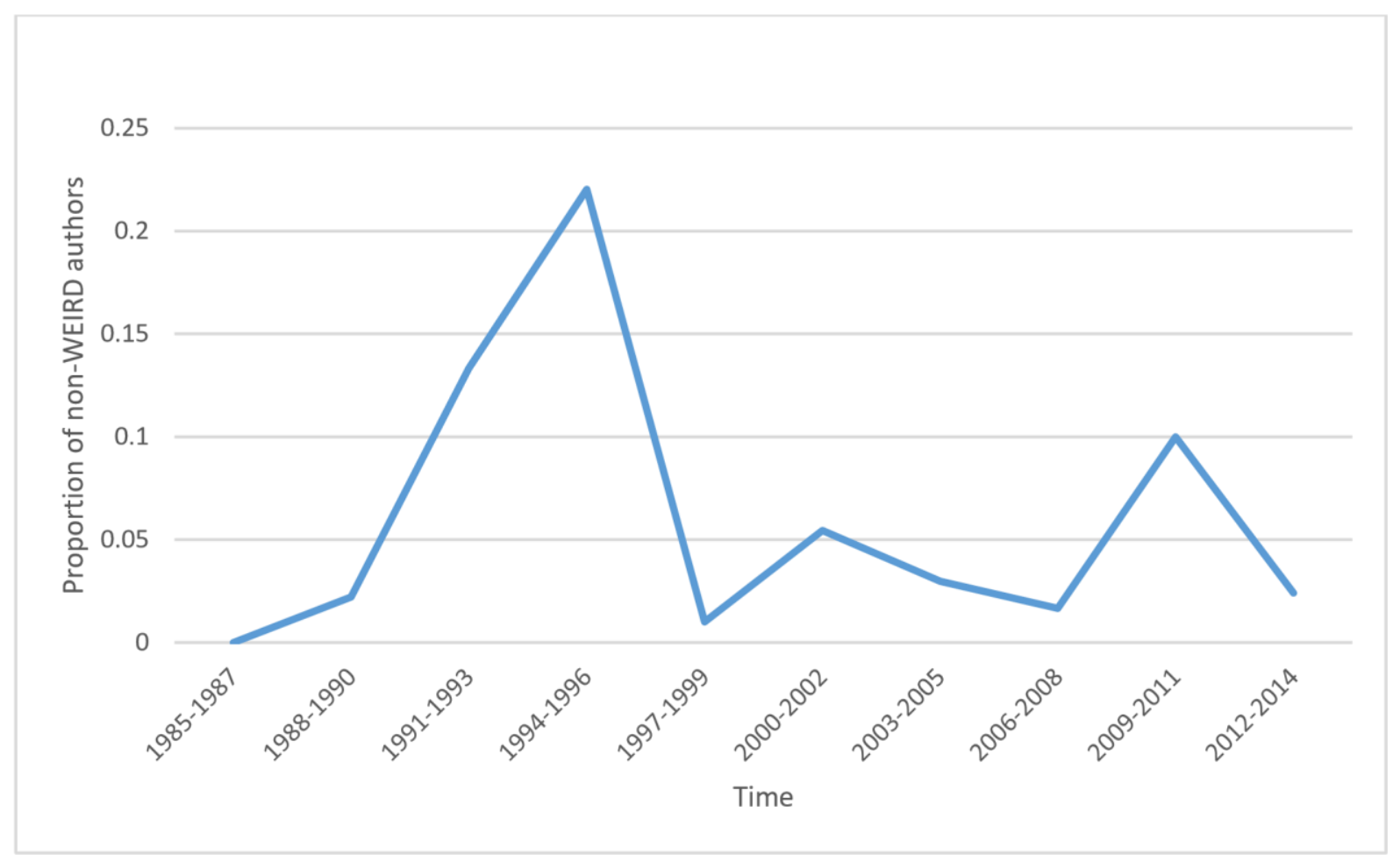

Figure 1. Line graph of non-WEIRD representation in the journal per three-year period.

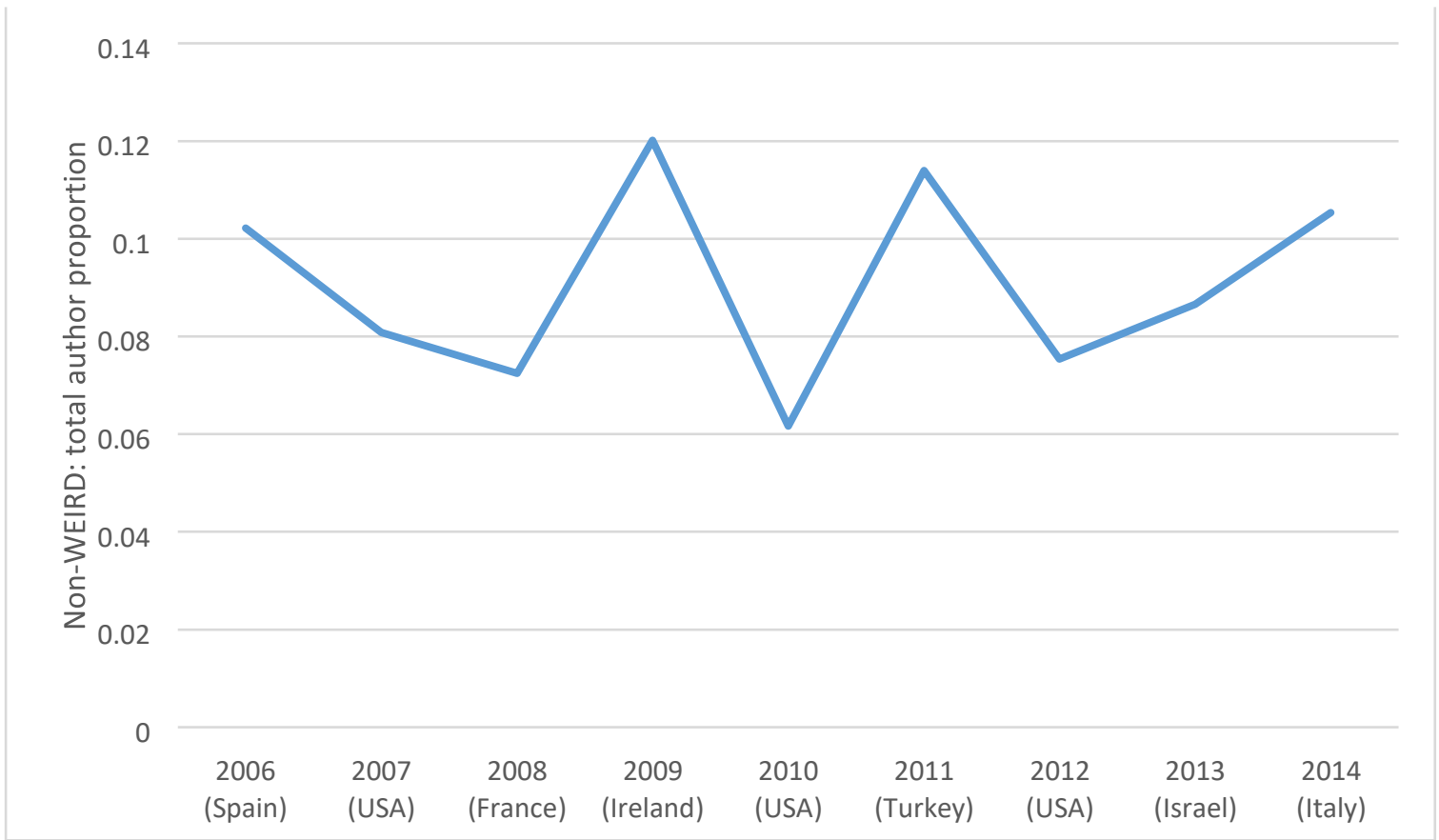

Figure 2. Line graph of non-WEIRD representation over the eight-year period in the ISPP annual meetings (note: country names refer to meeting venues). 


\section{TABLES}

Table 1

Count of unique WEIRD and non-WEIRD authors $(N=1,151)$ in the journal by country of affiliation in rank order (including isolates).

\begin{tabular}{|c|c|c|c|c|c|}
\hline \multicolumn{2}{|c|}{ WEIRD } & \multirow[b]{2}{*}{$\frac{\% \text { of }}{\text { total }}$} & \multicolumn{2}{|c|}{ non-WEIRD } & \multirow[b]{2}{*}{$\frac{\% \text { of }}{\text { total }}$} \\
\hline Country & $\underline{\text { N Authors }}$ & & $\underline{\text { Country }}$ & $\underline{\text { N Authors }}$ & \\
\hline USA & 722 & 66.4 & Japan & 10 & 15.9 \\
\hline United Kingdom & 64 & 5.9 & Poland & 8 & 12.7 \\
\hline Canada & 49 & 4.5 & South Africa & 7 & 11.1 \\
\hline Israel & 49 & 4.5 & Chile & 5 & 7.9 \\
\hline Germany & 37 & 3.4 & China & 5 & 7.9 \\
\hline Netherlands & 30 & 2.8 & Russia & 5 & 7.9 \\
\hline Australia & 27 & 2.5 & South Korea & 5 & 7.9 \\
\hline Italy & 25 & 2.3 & Bulgaria & 4 & 6.3 \\
\hline Belgium & 19 & 1.7 & Singapore & 3 & 4.8 \\
\hline New Zealand & 11 & 1.0 & Mexico & 2 & 3.2 \\
\hline Switzerland & 11 & 1.0 & Taiwan & 2 & 3.2 \\
\hline Denmark & 8 & 0.7 & Brazil & 1 & 1.6 \\
\hline Spain & 8 & 0.7 & Estonia & 1 & 1.6 \\
\hline Sweden & 7 & 0.6 & Hungary & 1 & 1.6 \\
\hline Austria & 3 & 0.3 & Serbia & 1 & 1.6 \\
\hline Finland & 3 & 0.3 & Slovakia & 1 & 1.6 \\
\hline France & 3 & 0.3 & Sri Lanka & 1 & 1.6 \\
\hline Norway & 3 & 0.3 & Venezuela & 1 & 1.6 \\
\hline Turkey $^{\mathrm{a}}$ & 3 & 0.3 & & & \\
\hline Ireland & 2 & 0.2 & & & \\
\hline Greece & 1 & 0.1 & & & \\
\hline Iceland & 1 & 0.1 & & & \\
\hline Malta & 1 & 0.1 & & & \\
\hline Portugal & 1 & 0.1 & & & \\
\hline Total & 1088 & $94.5 \%$ & Total & 63 & $5.5 \%$ \\
\hline
\end{tabular}

${ }^{a}$ The coding of Turkey as a WEIRD nation is awkward, as it is primarily a Muslim (but secular) society. However, under our operationalisation of Henrich et al.'s (2010) taxonomy, Turkey must be considered WEIRD. It is a member of the Western and Others Group (UNAIDS, The governance handbook, 2010), one of the members of the high-income OECD group, and classified as a 'newly industrialised country' (Bozyk, 2006), a member of the Council of Europe (COE, 2019) and has a democratically elected parliament. Turkey therefore met the basic criteria for being considered WEIRD. We acknowledge this as an edgecase that did not fit neatly into this dichotomy. 
Distance of WEIRD authors to nearest non-WEIRD author and non-WEIRD authors to nearest non-compatriot non-WEIRD author in the journal

\begin{tabular}{lcc}
\hline Distance & WEIRD to non-WEIRD $(\%)$ & non-WEIRD to non-WEIRD \\
\hline 1 & $61(5.73 \%)$ & $3(4.76 \%)$ \\
2 & $58(5.45 \%)$ & $7(11.11 \%)$ \\
3 & $41(3.85 \%)$ & $5(7.94 \%)$ \\
4 & $22(2.07 \%)$ & $1(1.59 \%)$ \\
5 & $1(0.09 \%)$ & - \\
0 (No Path) & $881(82.80 \%)$ & $47(74.60 \%)$ \\
\hline
\end{tabular}


Table 3

Independent samples t-tests comparing centrality percentages between WEIRD and non-WEIRD authors in the journal

\begin{tabular}{llcccccccc}
\hline $\begin{array}{c}\text { Centrality } \\
\text { type }\end{array}$ & \multicolumn{1}{c}{ Group } & $\mathrm{N}$ & Sum \% & Mean & SD & $d f$ & $t$ & $p$ & $d$ \\
\hline Degree & Non-WEIRD & 63 & 5.53 & 0.088 & 0.05 & 1125 & 0.112 & 0.911 & 0.015 \\
& WEIRD & 1,064 & 94.47 & 0.089 & 0.074 & & & & \\
Betweenness & Non-WEIRD & 63 & 4.87 & 0.077 & 0.353 & 1125 & 0.203 & 0.839 & 0.026 \\
& WEIRD & 1,064 & 95.14 & 0.089 & 0.469 & & & & \\
& Non-WEIRD & 63 & 7.04 & 0.112 & 0.086 & 1125 & 2.068 & 0.039 & 0.268 \\
Closeness & WEIRD & 1,064 & 92.96 & 0.087 & 0.091 & & & & \\
\end{tabular}


Table 4

Count of unique WEIRD and non-WEIRD authors in annual meetings by country of affiliation in rank order.

\begin{tabular}{|c|c|c|c|c|c|}
\hline \multicolumn{2}{|c|}{ WEIRD } & \multicolumn{4}{|c|}{ non-WEIRD } \\
\hline Country & $\mathrm{N}$ & $\%$ of total & Country & $\mathrm{N}$ & $\%$ of total \\
\hline USA & 1,577 & $37.6 \%$ & Poland & 70 & $1.7 \%$ \\
\hline UK & 340 & $8.1 \%$ & Russia & 61 & $1.5 \%$ \\
\hline Israel & 308 & $7.3 \%$ & Brazil & 46 & $1.1 \%$ \\
\hline Germany & 262 & $6.2 \%$ & Mexico & 42 & $1.0 \%$ \\
\hline Spain & 189 & $4.5 \%$ & South Africa & 38 & $0.9 \%$ \\
\hline Italy & 168 & $4.0 \%$ & Chile & 31 & $0.7 \%$ \\
\hline Netherlands & 119 & $2.8 \%$ & Argentina & 27 & $0.6 \%$ \\
\hline Canada & 109 & $2.6 \%$ & Hungary & 19 & $0.5 \%$ \\
\hline Turkey & 94 & $2.2 \%$ & India & 16 & $0.4 \%$ \\
\hline Australia & 77 & $1.8 \%$ & Indonesia & 13 & $0.3 \%$ \\
\hline Switzerland & 75 & $1.8 \%$ & Croatia & 12 & $0.3 \%$ \\
\hline Sweden & 61 & $1.5 \%$ & China & 11 & $0.3 \%$ \\
\hline Belgium & 58 & $1.4 \%$ & Finland & 11 & $0.3 \%$ \\
\hline Portugal & 55 & $1.3 \%$ & Romania & 11 & $0.3 \%$ \\
\hline Ireland & 34 & $0.8 \%$ & Serbia & 10 & $0.2 \%$ \\
\hline Austria & 31 & $0.7 \%$ & Japan & 9 & $0.2 \%$ \\
\hline France & 30 & $0.7 \%$ & Iran & 7 & $0.2 \%$ \\
\hline Greece & 27 & $0.6 \%$ & Venezuela & 7 & $0.2 \%$ \\
\hline Denmark & 23 & $0.5 \%$ & Lithuania & 6 & $0.1 \%$ \\
\hline New Zealand & 19 & $0.5 \%$ & South Korea & 6 & $0.1 \%$ \\
\hline Norway & 12 & $0.3 \%$ & Ukraine & 6 & $0.1 \%$ \\
\hline Scotland & 6 & $0.1 \%$ & Columbia & 5 & $0.1 \%$ \\
\hline \multirow[t]{23}{*}{ Iceland } & 1 & $0.0 \%$ & Taiwan & 5 & $0.1 \%$ \\
\hline & & & Azerbaijan & 4 & $0.1 \%$ \\
\hline & & & Cyprus & 4 & $0.1 \%$ \\
\hline & & & Latvia & 4 & $0.1 \%$ \\
\hline & & & Nigeria & 4 & $0.1 \%$ \\
\hline & & & Czech Republic & 3 & $0.1 \%$ \\
\hline & & & Estonia & 3 & $0.1 \%$ \\
\hline & & & Malaysia & 3 & $0.1 \%$ \\
\hline & & & Bulgaria & 2 & $0.0 \%$ \\
\hline & & & Egypt & 2 & $0.0 \%$ \\
\hline & & & Guam & 2 & $0.0 \%$ \\
\hline & & & Korea & 2 & $0.0 \%$ \\
\hline & & & Lebanon & 2 & $0.0 \%$ \\
\hline & & & Montenegro & 2 & $0.0 \%$ \\
\hline & & & Singapore & 2 & $0.0 \%$ \\
\hline & & & Slovakia & 2 & $0.0 \%$ \\
\hline & & & Cambodia & 1 & $0.0 \%$ \\
\hline & & & Costa Rica & 1 & $0.0 \%$ \\
\hline & & & Georgia & 1 & $0.0 \%$ \\
\hline & & & Herzegovina & 1 & $0.0 \%$ \\
\hline & & & Iraq & 1 & $0.0 \%$ \\
\hline & & & Kyrgyzstan & 1 & $0.0 \%$ \\
\hline & & & Macedonia & 1 & $0.0 \%$ \\
\hline
\end{tabular}




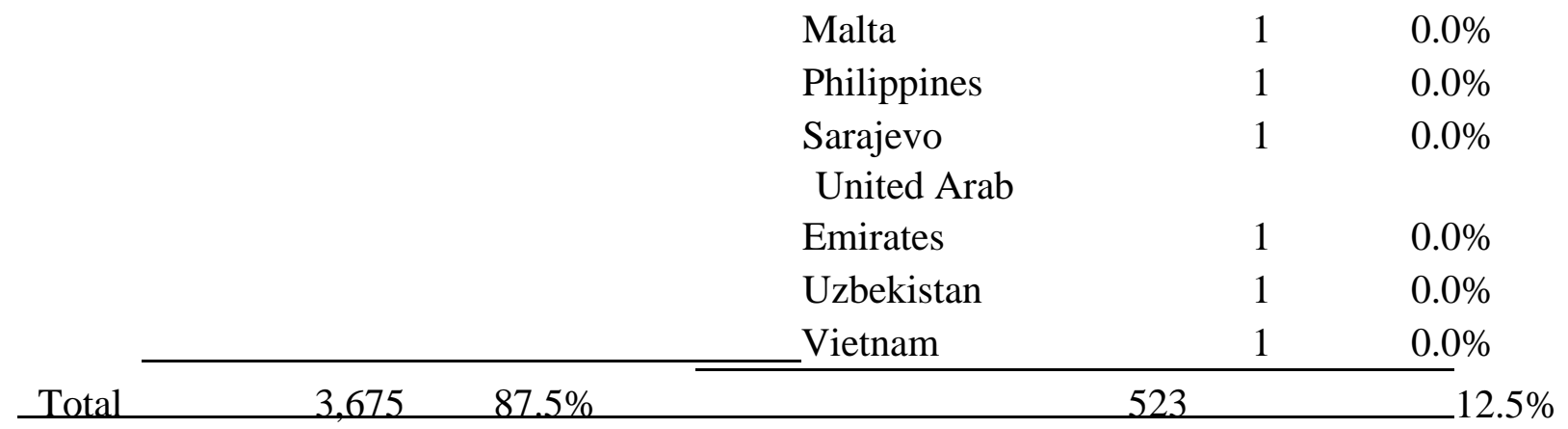


Table 5

Distance of WEIRD authors to non-WEIRD authors and non-WEIRD authors to noncompatriot non-WEIRD authors in annual meetings

\begin{tabular}{lcc}
\hline Distance & WEIRD:non-WEIRD & non-WEIRD:non-WEIRD \\
\hline 1 & $185(5 \%)$ & $24(4.6 \%)$ \\
2 & $408(11.1 \%)$ & $55(10.6 \%)$ \\
3 & $357(9.7 \%)$ & $24(8.3 \%)$ \\
4 & $240(6.5 \%)$ & $6(1.2 \%)$ \\
5 & $106(2.9 \%)$ & $1(0.2 \%)$ \\
6 & $48(1.3 \%)$ & - \\
7 & $23(0.6 \%)$ & - \\
8 & $10(0.3 \%)$ & $368(70.6 \%)$ \\
No Path & $2,292(62.5 \%)$ & \\
\hline
\end{tabular}


POLITICAL PSYCHOLOGY AUTHORSHIP NETWORKS 